\title{
Entre a alteridade e a indiferença: uma análise das relações na escola
}

\author{
Between otherness and indifference: an analysis of relations in school
}

\section{Entre alteridad y la indiferencia: un análisis de las relaciones en la escuela}

\author{
Marta Nidia VARELla Gomes MAIA* \\ ALESSANDRA EVELIN BRANDOLIM PACHECO** \\ PAULA LANNES PEREIRA PASSOS ${ }^{* * *}$
}

\begin{abstract}
RESUMO
Analisar relações e interações presentes na escola, a partir da obra de Martin Buber, é o que propõe o presente texto. Transitando entre recortes do cotidiano extraídos de dissertações de mestrado e teses de doutorado, e apoiado na concepção de existência humana e no conceito de relação buberianos, aponta para a possibilidade e necessidade de humanização nas interações. Inicia-se com a contextualização do campo empírico dos trabalhos selecionados, apresenta, brevemente, a filosofia antropológica de Martin Buber e destaca os conceitos estudados aplicados à análise das teses e dissertações. Conclui com considerações sobre o próprio processo de estudo e análise do material selecionado e sobre as contribuições das teorias de Buber para as relações entre os sujeitos na escola.
\end{abstract}

Palavras-chave: Criança. Escola. Relações. Interações. Humanização.

\begin{abstract}
Analyze relations and interactions present in school from Martin Buber's work is proposing this text. Moving between daily clippings extracted from dissertations and doctoral theses, based on the conception of human existence and the concept of buberianos relationship, points to the possibility and necessity of humanization in the interactions. Starting with the contextualization of the empirical field of the selected works, the text briefly presents the anthropological philosophy of Martin Buber, highlights the studied concepts applied to the analysis of theses and dissertations and concludes with considerations about the very process of study and analysis of the selected material and the contributions of the theories of Buber for relations between subjects in school.
\end{abstract}

Keywords: Child. School. Relations. Interactions. Humanization.

\section{RESUMEN}

Analizar las relaciones e interacciones presentes en la escuela a partir de la obra de Martin Buber está proponiendo este texto. Moviéndose entre recortes de diarios extraídos de disertaciones y tesis doctorales, basado en la concepción de la existencia humana y el concepto de buberianos relación, apunta a la posibilidad y necesidad de humanización en las interacciones. A partir de la contextualización del campo empírico de las obras seleccionadas, el texto presenta brevemente la filosofía antropológica de Martin Buber, pone de relieve los conceptos estudiados aplicados al análisis de las tesis y disertaciones y concluye con consideraciones sobre el propio proceso de estudio y análisis del material seleccionado y los aportes de las teorías de Buber para las relaciones entre los sujetos en la escuela.

Palabras clave: Niños. Escuela. Relaciones. Interacciones. Humanización.

\footnotetext{
* Mestra em Educação pela Pontifícia Universidade Católica do Rio de Janeiro. Supervisor Educacional MTD II da Fundação Pública Municipal de Educação de Niteroi, Rio de Janeiro.E-mail: <marta965@globo.com>.

** Bolsista de iniciação científica no Grupo de Pesquisa Infância, Formação e Cultura - INFOC.

*** Pedagoga. Mestranda do Departamento de Educação da PUC-Rio.
} 


\section{INTRODUÇÃO}

As relações na escola são instigantes e complexas, envolvem uma diversidade de fatores e uma pluralidade de pessoas - professores, alunos, gestores e se estendem às famílias e à comunidade. Pensar a escola requer conhecer e compreender as relações sociais vividas e expressas nas práticas pedagógicas, repletas de sentidos e significados e processos de interação.

"Entre a alteridade e a indiferença" evidencia os paradoxos e as ambiguidades que podem representar as relações nas instituições educacionais; o lugar em que se colocam professores, pesquisadores e alunos; o significado e a concepção de infância na ótica desses diversos sujeitos sociais; e como ressignificam as práticas pedagógicas partindo de sua compreensão de ser e existir. O texto transita da rudeza à sensibilidade presentes nas relações, fazendo apontamentos, destacando singularidades, desejando contribuir para relações e práticas mais humanizadas. Para esse fim, adotou-se como estratégia metodológica a seleção de pesquisas que tratassem do tema, a fim de analisá-las e visitar seu campo, para acolhêlo e dialogar com ele, de outro lugar. Entre os trabalhos escolhidos, há duas teses e quatro dissertações produzidas por um grupo de pesquisa interinstitucional que, durante sua trajetória, tem se dedicado a estudar a infância e a educação.

Como fundamentação teórica, tomou-se a obra de Martin Buber (1878-1965). Sua concepção de existência humana e seu conceito de relação nortearam o exame do material selecionado, possibilitando atribuir novos sentidos às interações e práticas. Ao estudá-lo, foram identificados e selecionados alguns conceitos de sua teoria:: alteridade; respeito e reconhecimento; desconhecimento do outro; couraça; discriminação, estereótipo e preconceito; e indiferença, que auxiliaram nesta análise (BUBER, 2003, 2009). A primeira parte deste texto traz a contextualização do campo empírico dos trabalhos selecionados; em seguida, apresenta, brevemente, a filosofia antropológica de Martin Buber. $\mathrm{Na}$ terceira parte, destaca os conceitos estudados aplicados à análise das teses e dissertações.

\section{Contextualização do CAMPO EMPÍRICO}

Este tópico contextualiza os trabalhos que compõem o material empírico, seus temas, espaços, objetivos e metodologia. Em relação aos temas, Oliveira (1998) estuda a religião, Moura (2005) traz a arte, Lima (2006) trabalha com a identidade étnica, Freire (2008) aborda o espaço de lazer da cidade, Toledo (2010) versa sobre as relações da criança com a natureza, Maia (2011) discute o currículo. Nesse conjunto foram pesquisadas escolas de educação infantil, uma escola de ensino fundamental, uma creche comunitária, uma escola dominical e um projeto educativo que funciona em um museu.

Oliveira (1998) objetivou investigar as práticas disciplinares utilizadas com as crianças em uma creche comunitária e numa escola dominical de uma instituição religiosa. Usou como metodologia observação, entrevistas, análise documental e registro diário de trabalho de campo.

Moura (2005) acompanhou o Programa Educativo do Museu de Arte Moderna (MAM) do Rio de Janeiro, tendo como foco as crianças, os jovens e os professores em visitas escolares e os profissionais responsáveis por esse atendimento. Seu trabalho buscou fazer uma reflexão sobre a educação artística, a partir da leitura e análise de documentos oficiais que retratam o grau de interesse das políticas públicas voltadas para a questão.

Lima (2006) apresenta um estudo de caso sobre as práticas cotidianas da escola e sua relação com as identidades étnicas das crianças, focalizando a perspectiva afrodescendente, realizada em uma instituição de ensino fundamental. As estratégias metodológicas contaram com observação do campo, entrevista, análise documental, registro diário de trabalho de campo e oficina realizada com as crianças.

Freire (2008) estudou uma escola de educação infantil, em uma turma de crianças de 4 e 5 anos, acompanhando diariamente suas atividades escolares. Como estratégias metodológicas, a pesquisadora contou com observação, conversas com crianças e professoras e descrições densas de fatos e situações vistos e vividos.

Toledo (2010) teve como objeto de estudo as relações entre as crianças e a natureza em uma escola de educação infantil da rede pública de um município da Região Metropolitana. Foram realizadas observações, registros fotográficos, oficina com as crianças, entrevista e questionário.

Maia (2011) pesquisou duas escolas públicas de educação infantil de um município da Região Metropolitana do Rio de Janeiro, com o objetivo de compreender por que essas escolas organizam seu currículo em torno de datas comemorativas do calendário civil e religioso. Suas estratégias metodológicas foram a observação da prática pedagógica e os momentos de planejamento, questionário, análise de documentos e entrevistas.

\section{A Filosofia ANTropológica DE BUBER}

Ao adotar como fundamentação teórica a filosofia antropológica de Martin Buber, educa-se o olhar para compreender de outra forma as interações de e entre 
crianças e adultos e as práticas pedagógicas presentes nas pesquisas estudadas. O objetivo é desvelar e produzir novo significado para as relações na escola.

O filósofo e teólogo Martin Buber nasceu em Viena, em 1878, viveu seus últimos anos em Jerusalém, onde faleceu em 1965. Seus estudos ressaltam que, sem o diálogo, não há existência. Sua filosofia do diálogo está no centro de toda sua reflexão, tanto no campo da filosofia como da religião, da política, da sociologia e da educação (ZUBEN, p. IX, in BUBER, 2003). A responsabilidade do ser humano pelo seu próximo está presente em toda a sua obra, desde o livro Eu-Tu (2003). Essa responsabilidade vincula a reflexão e a ação, a práxis e o logos. Sua própria vida é a fonte de seu pensamento e sua existência, a manifestação concreta de suas convicções (ZUBEN, p. VI, in BUBER, 2003).

Para Buber (2003, p. 3), "o mundo é duplo para o homem, segundo a dualidade de sua atitude". Essa dualidade de atitude é realizável em duas palavrasprincípio, que são pares de palavras indissociáveis, Eu-Tu e Eu-Isso. São duas formas de estar no mundo. Quando se pronuncia $\mathrm{Tu}$, não se pronuncia Isso e vice-versa. No entanto, ao se proferir Tu ou Isso, profere-se o Eu. Não existe o Eu em si, mas apenas ligado a uma dessas palavras-princípio. A filosofia de Buber é um convite a uma forma de estar no mundo, um convite a saber ser EuIsso sem perder a dimensão de ser Eu-Tu. Nessa forma de estar no mundo, em constante exercício de alteridade, o respeito pelo outro se manifesta. Na relação $\mathrm{Eu}-\mathrm{Tu}$, a pessoa assume uma atitude de não usar o outro para coisa alguma, uma vez que o Eu "não tem coisa alguma por objeto" (BUBER, 2003, p. 5). Sobre essa palavraprincípio, Buber argumenta:

A relação com o TU é imediata. Entre o EU e o TU não se interpõe nenhum jogo de conceitos, nenhum esquema, nenhuma fantasia e a própria memória se transforma no momento em que passa dos detalhes à totalidade. Entre o EU e o TU não há fim algum, nenhuma avidez ou antecipação; e a própria aspiração se transforma no momento em que passa do sonho à realidade. Todo meio é obstáculo. Somente na medida em que todos os meios são abolidos, acontece o encontro (BUBER, 2003, p. 13).

A relação Eu-Tu é dialógica. No diálogo, há um elemento constituinte, "a reciprocidade da ação interior” (BUBER, 2009, p. 41). Para existir diálogo, é necessário haver reciprocidade. Não basta apenas que duas pessoas estejam falando. É necessário que estejam dialogicamente ligadas, voltadas uma à outra. Quando estamos em diálogo com o outro, não estamos sós, mas em uma existência dialógica, que "recebe, mesmo no extremo abandono, uma sensação áspera e revigorante de reciprocidade" (BUBER, 2009, p. 55), pois o dialógico é "um comportamento dos homens um-para-com-o-outro" (BUBER, 2009, p. 40).

No relacionamento Eu-Isso, a atitude é outra. O Eu do relacionamento experimenta, percebe, representa, utiliza, quer, planeja, sente ou pensa em alguma coisa. Nos termos de Buber:

[...] o Eu, portanto, com o qual nenhum Tu está facea-face presente em pessoa, mas que é cercado por uma multiplicidade de "conteúdos" tem só passado, e de forma alguma presente. Em outras palavras, na medida em que o homem se satisfaz com as coisas que experiência e utiliza, ele vive no passado e seu instante é privado de presença. Ele só tem diante de si objetos, e estes são fatos do passado (BUBER, 2003, p. 14).

Não se pode incorrer no erro de pensar que um está relacionado ao bem e o outro ao mal. Buber não admite essa simplificação. Na coletânea "Do diálogo e do dialógico", esclarece: "O homem não é bom, o homem não é mau, ele é, no sentido eminente, bom-e-mau" (BUBER, 2009, p. 127). Dessa forma, "a palavra princípio Eu-Isso não tem nada mal em si porque a matéria não tem nada de mal em si mesma. O que existe de mal é o fato de a matéria pretender ser aquilo que existe" (BUBER, 2003, p. 54).

Porém, o "homem não se aproxima do mundo somente através de experiências" (BUBER, 2003, p. 5). Não se é somente Tu ou somente Isso, mas se é o Tu e o Isso, já que "o Isso é a crisálida, o Tu a borboleta" (BUBER, 2003, p. 20). Para Buber (2003, p. 20), eles "são processos que se entrelaçam confusamente numa profunda dualidade".

As palavras princípio, (?) se pudessem ser analisadas de forma linear, estariam em pontos extremos, comportando entre esses pontos as formas mais próximas de uma ou de outra. Indo da relação Eu-Tu, que é presença e atualidade, ao Eu-Isso, que é a experiência com o mundo. Na palavra princípio $\mathrm{Eu}-\mathrm{Tu}$, o Eu sente o Tu, seu outro. Essa relação acontece em presença do $\mathrm{Eu}$ e do $\mathrm{Tu}$ e, quando toma consciência da própria relação, o homem dela se afasta. A tomada de consciência da relação interrompe seu êxtase e intensidade e a torna uma relação Eu-Isso. Uma relação que tem a percepção objetiva de si, do outro e do mundo. Porém, segundo Buber (2003, p. 74), “o Eu que se separa do evento de relação em direção da separação, consciente desta separação, não perde sua atualidade. A participação permanece nele, conservada como potencialidade viva... e que pode ser aplicada a todas as relações, a semente permanece nele".

Para viver no mundo, o homem precisa do relacionamento Eu-Isso, ter consciência e relação com as coisas do mundo. Através do relacionamento Eu-Isso, o homem mantém e constrói a vida, mas é na relação $\mathrm{Eu}-\mathrm{Tu}$ que ele se qualifica para a vida, que realiza sua 
humanidade. Buber diz: "O homem não pode viver sem o Isso, mas aquele que vive somente com o Isso não é homem" (BUBER, 2003, p. 39).

$\mathrm{Na}$ obra de Buber, encontram-se diferentes formas de caracterizar a relação que é presença e atualidade com o outro e o relacionamento que é presença no mundo. Um grupo dessas diferentes formas - alteridade, respeito/ reconhecimento, desconhecimento do outro, couraça, discriminação/estereótipo/preconceito, indiferença - é instrumento das análises deste trabalho. Esses conceitos são apresentados a seguir, relacionados aos recortes extraídos das teses e dissertações.

\section{OLHARES SOBRE O CAMPO}

\section{1"Vamos fazer um castelo só?! Meu e seu?" - ALTERIDADE}

Alteridade é um conceito que transita em toda a obra de Buber. No livro Do Diálogo e do Dialógico, o autor afirma que para entrar na vida dialógica é preciso perceber e aceitar o outro na sua totalidade, voltar-se para o outro, perceber a sua presença, superando a indiferença em relação a ele. Buber explica que:

Somente aquele que se volta para o outro homem enquanto tal e a ele se associa recebe neste outro o mundo. Somente o ser cuja alteridade, acolhida pelo meu ser, vive face a mim com toda a densidade da existência é que me traz a irradiação da eternidade. Somente quando duas pessoas dizem, uma-à-outra, com a totalidade dos seus seres: 'és tu!' é que se instala entre elas o Entre (BUBER, 2009, p. 65).

A compreensão de alteridade na filosofia buberiana é complementada por Zuben (in BUBER, 2003). Esse autor a descreve como algo que ocorre a partir da relação: "A resposta instaura o diálogo, a inter-ação onde o Eu confirma o Tu em seu ser e é por ele confirmado. O Eu exerce uma ação, atua sobre o Tu e este atua sobre o Eu. Neste encontro se estabelece a alteridade na medida em que existe uma alteração mútua" (ZUBEN, p. 162-163 in BUBER, 2003). O movimento de alteridade está relacionado à palavra princípio Eu-Tu: "A alteridade essencial se instaura somente na relação Eu-Tu; no relacionamento Eu-Isso, o outro não é encontrado como outro em sua alteridade" (ZUBEN, p. LII, in BUBER, 2003).

Compreendendo a alteridade como um princípio para a vida dialógica, buscou-se presenciar situações que anunciassem a dialogicidade nas interações e práticas pedagógicas descritas nas teses e dissertações lidas. Essas situações evidenciaram uma maior frequência da relação de alteridade nas interações de crianças entre si e em momentos de diálogo com a pesquisadora. Houve pouca recorrência de situações que apresentassem uma relação de alteridade entre adultos (escola e/ou museu) ou entre adultos e crianças. O texto a seguir registra um diálogo entre elas em um momento de brincadeira na escola, no qual a alteridade permeia a relação:

Fernando: meu castelo vai ficar muuuuuuito mais alto que o seu! Clarice: e daí? O meu vai ficar mais bonito. Vou botar jardim e flores. Fernando: o meu vai ter carro na garagem. Na casa do meu tio tem carro na garagem. Ele nem deixa a gente entrar para brincar. Clarice: quando eu crescer vou querer também uma casa com carro na garagem. Deve ser bom. Quando o carro sai, a gente tem a garagem para brincar. Fernando: você vai em alguma casa que tem carro na garagem? Clarice: não. Mas o seu Paulo tem, lá perto de casa, pai do Tiago. Eu brinco com o Tiago, mas nem vou na casa dele. Fernando: vamos fazer um castelo só? Meu e seu? Clarice: vamos! Daí vai ter jardim, flor e carro na garagem (FREIRE, 2008, p. 125).

Nessa conversa entre crianças, vida e fantasia constituem o enredo dialógico. Numa relação horizontal, pontos de vista são postos ao crivo de um outro e se complementam numa perspectiva de aceitação e conhecimento sobre o outro. A alteridade, nesse sentido, instaura o "nosso" ao proporcionar a superação das diferenças. Na situação abaixo, que narra uma interação entre pesquisadora e crianças, a alteridade aparece como uma ponte entre adulto e criança:

Pesquisadora: Você gosta de ouvir música? Nayana: Gosto. Lá em casa, a gente ouve sempre. Pesquisadora: E ouve o quê? Nayana: Funk, pagode. Sabe aquela música dos Travessos? (começa a cantarolar uma música romântica, açucarada). Pesquisadora: Não, não conheço. Nayana: Minha mãe adora. Ouve todo dia e canta alto para caramba. Até os vizinhos pedem pra ela abaixar o rádio. Até chora! Pesquisadora: Você também gosta dessa música? Nayana: Ah! Gosto, né! Mas prefiro funk. É mais animado e dá para dançar. Pesquisadora: E você? Gosta de ouvir música em casa? Fernando: Eu gosto. Gosto mais do Zeca Pagodinho porque meu padrasto ouve ele muito, 'daí aprendi'. Pesquisadora: Ah! Sei. Também gosto do Zeca. Fernando: (me olha espantado) é mesmo, tia? Que 'manero'! Vou até falar para o meu padrasto. Você sabe cantar alguma música dele? Pesquisadora: Sei um monte! Quer ouvir? Então, começa a cantarolar vários pedaços de sambas do Zeca Pagodinho, pois gosta mesmo e tem os discos dele em casa. Fernando a acompanha em várias, sabe as letras, não erra as melodias, canta alto, lembra-se de outras. Ri alto e se diverte. Até ensaia uns passos de samba. Seus olhos brilham, pega na mão da pesquisadora para que se levante e dance com ele. Resiste. Ele continua cantando e dançando (FREIRE, 2008, p. 134). 
A pesquisadora, ao entabular um diálogo com as crianças, tem a oportunidade de conhecê-las. Ao voltar-se para o outro, o Fernando, ela se aproxima e se encontra com ele em sua plenitude, e este se volta para ela, estabelecendo a "inter-ação". Esse encontro gera algo que merece ser contado. Fernando tem algo que alguém (o padrasto) vai querer ouvir. O encontro transforma ambos. Na relação de alteridade, há o que contar. A pessoa, a criança, pôde ser encontrada em sua inteireza por alguém que foi ao seu encontro. O diálogo verdadeiro, aquele em que há encontro e reciprocidade, num exercício de alteridade, é o que abre a pessoa em sua inteireza à outra.

$\mathrm{Na}$ interação descrita entre pesquisadora e criança, pode-se observar que na relação de alteridade há encontro e diálogo verdadeiro e, segundo Buber, durante esse encontro não é possível haver uma reflexão sobre a relação ou sobre o outro da relação. Contudo, quando a relação de alteridade deixa de ser presença e se distancia, pode, porque foi dialógica, gerar o respeito e o reconhecimento.

\section{2 "Também ajudo ela quando eles xingam" - RESPEITO E RECONHECIMENTO}

Respeito e reconhecimento são conceitos que podem ser pensados a partir da obra de Martin Buber, na perspectiva de ocorrerem mediante uma relação dialógica, a relação em si. Para que a pessoa possa fazer um reconhecimento do/sobre o outro, faz-se necessário certo distanciamento, um afastamento que permite dirigir o olhar para o ser e reconhecê-lo como outro, após a atualidade da presença, que transformou os dois seres. Sob esse aspecto, esses conceitos se alinham à palavraprincípio Eu-Isso, pois estão no âmbito da experiência que o encontro com o outro possibilita ao findar-se em seu êxtase. De acordo com o autor, "a palavra-princípio Eu-Isso torna-se possível, através desse conhecimento, através da separação do Eu" (BUBER, 2003, p. 25) e "somente agora o $\mathrm{Tu}$, originalmente inexperienciável, só agora recebido, torna-se um Ele ou Ela". (BUBER, 2003, p. 22). Dessa forma, o "reconhecimento" compreende a percepção e a aceitação do outro como "outro alguém". É isso que evidencia o texto abaixo entre uma pesquisadora e duas crianças:

[Na sala de aula] Durante a elaboração de um desenho (...). A professora, após cerca de dez minutos, passou para ver quem já havia desenhado e quando chegou na carteira de uma aluna, perguntou: 'Você não fez?' 'Eu não sei', a aluna responde. Ao que ela diz que tudo bem, de outra vez ela fará. Dou um tempo, me aproximo dela e tento puxar conversa: 'E então, cadê seu desenho?' Silêncio... Insisto: 'Você já guardou o seu desenho? Posso ver?' Gesto de negação com a cabeça. 'Por quê? Não gostou do desenho?' Resposta: negação com a cabeça.

'Mostra para mim. Tenho certeza de que vou gostar.' Nessa hora, Abayomi se aproxima falando: 'Ela não fez, tia. Porque acha que os meninos vão zoar dela'. Pergunto por que e Abayomi diz: 'Porque eles zoam dela'. 'Mas por que?', pergunto. E é Kiara que finalmente abre a boca: 'Porque eles são uns idiotas e não respeitam os outros'. E Abayomi completa: 'É. Eles implicam com o cabelo dela. Dizem que é de Bombril'. Aproveito e pergunto: 'Mas por que eles fazem isso?'. E Abayomi, falante, toma a frente: 'Ela já disse, tia. Porque eles são idiotas e não gostam de negro'. 'Mas por que eles não gostam de negro?', insisto. 'Ah, sei lá! Porque são idiotas.' 'E com você, já implicaram?' 'Sim, quando eu botei trança da primeira vez. Me chamaram de cabelo de barbante, mas dei uns tapas neles. Disse que ia chamar meu tio, para eles dizerem isso e disse para a tia. Também ajudo ela (Kiara) quando eles xingam. Eu ajudo você a desenhar, Kiara.' - 'E o que a professora fez com eles, com os meninos que mexem com você e com sua colega?' 'Manda eles pararem de implicar com os outros. Mas eles são teimosos. Posso ajudar ela a fazer, tia?' Olhei para a professora que continuava olhando os desenhos das outras crianças e respondi: 'Sim, você pode, se quiser.' (LIMA, 2006, p. 166).

Nessa interação, Abayomi reconhece Kiara ao se colocar em seu lugar, pois ela também já havia sido alvo de preconceitos e sabia que a menina não queria mostrar seu desenho por medo de ser ridicularizada; as marcas deixadas pelo preconceito são compartilhadas por ambas. A busca da pesquisadora em saber qual era o motivo pelo qual Kiara não havia feito o desenho demonstra respeito e reconhecimento pela criança e uma não indiferença à situação vivida. A fala final, na qual consente que Abayomi ajude Kiara a fazer o desenho, é uma resposta a ao anseio da Abayomi de ajudá-la. A pesquisadora responde à criança, ocupando um lugar nesse diálogo, marcando sua presença e instaurando uma relação Eu-Tu. Essa interação ajuda a pensar sobre a postura do pesquisador ante o campo de pesquisa e sujeitos pesquisados. O respeito e o reconhecimento evidenciados na situação descrita equivalem à resposta responsável ou responsividade do investigador diante da pessoa pesquisada, a criança, conferindo a ela visibilidade, num exercício de reciprocidade, que autentica a relação e instaura a confiança.

$\mathrm{Na}$ conversa entre as crianças e a monitora do museu, em uma visita da turma da 4⿳亠丷a série do ensino fundamental a uma exposição, novamente respeito e reconhecimento estão presentes: 
Monitora 1: O que vocês estão vendo? Criança: Um globo como se fosse uma cabeça. Criança: O mundo é uma cabeça. Monitora 1: (Repete as falas das crianças como se tivesse a intenção de garantir que todos se escutem e que possam compartilhar as ideias) Olha quanta coisa a gente já pensou aqui. O mundo é uma cabeça. Será que a gente pode pensar o contrário? Que a cabeça é um mundo? Olha quantas ideias! (E começa a repetir as falas inaudíveis das crianças que se manifestaram ao seu redor para o grupo). É uma cabeça, o mundo é uma cabeça, uma cabeça terrestre, o mundo pensa, olha quanta coisa! Olha só, se fosse um desenho de um mundo só, a gente ia pensar tudo isso? Crianças: Não. Claro que não (MOURA, 2005 p. 92).

Embora a monitora, a princípio, pareça estar preocupada em tratar do conteúdo, ela na realidade respeita e reconhece as crianças ao procurar dar visibilidade a elas, repetindo as falas daquelas que pronunciam muito baixo, valorizando-as, trazendo as crianças para a conversa. O respeito e o reconhecimento tornam audível a voz do outro, e não há como ouvir o outro e dizer ao outro, sem antes reconhecê-lo.

Os registros acima demonstram que o respeito e o reconhecimento, resultantes de uma relação em que há alteridade, podem ocorrer em diversas situações cotidianas. Buber ressalta a importância da ação, da realização, mostrando que é possível agir no cotidiano, e é essa ação simples do dia a dia que faz com que todos se tornem presentes no mundo. Contudo, é tão necessário falar da presença quanto da ausência, pois uma ajuda a entender a outra. É porque existe a presença que se pode falar em ausência. No próximo item é abordado o desconhecimento do outro, conceito de Buber que trata dessa ausência, dessa invisibilidade.

\section{3 "Na sala vai ser um transtorno!" - DESCONHECIMENTO DO OUTRO}

O desconhecimento do outro é o oposto da alteridade. Enquanto na alteridade o ato característico é o "ato de voltar-se-para-o-outro, completando-o" (BUBER, 2009, p.58); o que leva ao desconhecimento do outro é o ato de "dobrar-se-em-si-mesmo". Esse ato caracteriza-se por "retrair-se do homem diante da aceitação, na essência do seu ser, de uma outra pessoa na sua singularidade [ ] denomino dobrar-se-em-si-mesmo a admissão da existência do outro somente sob a forma da vivência própria, somente como 'uma parte do meu eu" (BUBER, 2009, p. 58).

Ao dobrar-se-em-si-mesmo, a pessoa vê, conhece, percebe a existência do outro, mas não o sente em presença, porque não lhe toca o ser e por ele não é tocado. Logo o que vê é exterioridade que percebe como algo de si mesmo. Vê o que quer, o que pode, o que consegue centrado em si, a partir de si e não em encontro com o outro. $\mathrm{O}$ outro tem uma aplicabilidade para si, a partir do que consegue compreender como o outro.

Nos recortes que se estudou, encontrou-se o desconhecimento do outro como uma categoria presente nas relações de cunho pedagógico, que têm uma intenção de ensino. São relações nas quais não há diálogo entre os envolvidos, crianças e adulto. As decisões sobre o que a criança vai fazer ou do que vai participar passam por critérios e motivos que não a vislumbram como pessoa na sua inteireza, mas como aluno a ser ensinado, ocupado, orientado. Não que seja ignorada, apenas não é reconhecida como o sujeito da ação. Veja-se:

Refeitório. São 7:30h. As crianças das turmas de Natalia e Evelyn, que tomam o café no mesmo horário todos os dias, conversam animadamente. Não há sol, faz frio e cai uma chuvinha fina. A professora de Educação Física ainda não chegou. Evelyn e Natalia conversam sobre o que fazer com as crianças. Hesitam entre irem para o parque mesmo com a chuva ou irem direto para a sala. Natalia: 'E então, o que você acha?'. Evelyn: 'Vamos para o parque assim mesmo. Não está chovendo muito e na sala vai ser um transtorno!' Natalia: 'É, elas vão ficar agitadas dentro da sala sem ter o que fazer nesse tempo até a Educação Física. Vamos para o parque pelo menos até $08: 15$ h'. Evelyn: 'Então vamos!'. Saímos todos do refeitório e rumamos para o parque. A areia está molhada e os brinquedos também. As crianças parecem gostar e correm para brincar. Depois de alguns minutos, a chuva aperta e as crianças, obedecendo ao chamado das professoras, saem correndo para dentro da escola. Natalia vai até a sala de leitura e tenta pegar um filme para passar no salão. Se encaminham todos para lá. As crianças estão alvoroçadas. Não teve parque, mas vai ter filme! Elas conversam muito, discutem sobre qual filme vão ver, etc. O filme não veio. Não teve jeito, cada uma das professoras pega sua turma e se encaminha para a sala de aula, são 8:10h. Às 8:30h vai começar a aula de Educação Física. Até lá Natalia distribui brinquedos diversos e coloca sobre as mesas para as crianças escolherem com o que querem brincar. Ela passeia pela sala e parece não saber bem o que fazer. Pega o caderno de planejamento, lê algumas folhas e guarda. Olha a lista de chamada, abre um armário e começa a arrumar gavetas deixando que as crianças brinquem sem a sua interferência (FREIRE, 2008, p. 121).

Diante da impossibilidade de ir ao pátio por causa da chuva e de assistir ao filme, a professora ficou sem saber o que fazer. Sua hesitação aponta um possível desconhecimento de si mesma, de suas possibilidades e potencialidades como professora. Uma alteração na rotina precisa ser preenchida e isso não passa por uma alternativa combinada ou compartilhada com as crianças. As crianças brincam até a hora da Educação Física, mas 
não contam com a participação ou atenção por parte da professora. Ela apenas demonstra querer encontrar algo para ocupar o tempo até que a outra aula comece. Não há uma preocupação em realizar uma atividade com as crianças.

O desconhecimento do outro impede que a professora esteja presente com as crianças, que viva aquele momento com elas, que partilhe sua angústia de não saber o que fazer, já que por causa da chuva não puderam ficar no pátio, e pedir para as crianças pensarem com ela atividades para fazerem enquanto a aula de Educação Física não começa.

\section{4 "Linha amarela" - COURAÇA}

Desconhecer-se e ao outro produz distância e afastamento. A ausência do encontro e presença entre as pessoas as direciona cada vez mais à forma de estar no mundo relacionada à existência limitada ao universo do Isso, da exterioridade, experiência e objetividade. No mundo do Isso, não estamos entregues ao encontro e à presença do outro, ainda assim, "cada ISSO pode, se entrar no evento da relação, tornar-se um TU" (BUBER, 2003, p. 38). Buber afirma que, sem ele (o mundo do ISSO), não podemos subsistir, mas a existência somente nele é como o nada, equivale a não ser, à inatualidade. $\mathrm{O}$ mundo do ISSO ausente do mundo do TU intimida, invade, e para que se proteja, cria-se uma couraça.

\begin{abstract}
Cada um de nós está preso numa couraça, cuja tarefa é repelir signos. Signos nos acontecem sem cessar. Viver significa ser alvo da palavra dirigida; nós só precisaríamos tornar-nos presentes, só precisaríamos perceber. Mas o risco nos é por demais perigoso, trovões silenciosos parecem ameaçar-nos de aniquilação: e aperfeiçoamos, de geração em geração, o aparato de defesa (BUBER, 2009, p. 43).
\end{abstract}

Esse aparato de defesa permite atravessar diferentes situações no mundo da experiência sem sobressaltos. A couraça é necessária para a praticidade da vida, mas ela também pode se tornar um anteparo à própria vida em seu sentido pleno, do encontro.

Cada um de nós está preso numa couraça que, graças à força do hábito, deixa logo de sentir. São apenas instantes que atravessam a couraça e que incitam a alma à receptividade. E quando tal instante agiu sobre nós e nos tornamos então atentos, perguntamo-nos: 'Que é que aconteceu aí de peculiar? Não era algo semelhante ao que me acontece todos os dias?', então podemos nos responder: 'Realmente, nada de peculiar aconteceu, é assim todos os dias, só que nós não estamos aí presentes todos os dias.' (BUBER, 2009, p. 43).

Não há como não ter couraça. Como diz Buber, todos estão presos em uma couraça. Desde pequenos, apren- de-se a se fechar diante de algumas situações. Percebe-se que não é possível falar tudo o que se pensa, que existem normas de conduta a seguir. A couraça, nesse sentido é um anteparo, uma proteção. Mas, não só repele o que é ruim, como também não deixa entrar aquilo que pode ser bom. Torna as relações impermeáveis e não permite que se conheça o outro. Não há abertura.

$\mathrm{Na}$ 4a--feira houve uma troca de horários entre a professora e uma colega. Essa colega comenta na reunião a agitação da turma e a professora da turma diz como resolve: 'Linha amarela já. Vou fechar o olho e quando abrir quero ver todos na linha amarela.' As outras professoras comentam que 'eles são muito agitados.' Professora da turma: 'São horríveis. Também me deram tudo de ruim. É o que deu.' Eu digo a eles: 'A minha esperança com vocês é que ano que vem não vão estar na escola, vão para a alfa.' As colegas riem. Ela diz: 'É mesmo. Eles vão embora.' (MAIA, 2010, p. 102).

A professora ocupa um lugar superficial nessa relação. Na dificuldade de encontrar saídas para conseguir resolver o problema da turma, prefere transferir o seu insucesso para as crianças, ao invés de buscar com elas novos caminhos. Prende-se em um estereótipo, das crianças serem agitadas e horríveis, como justificativa de suas ações. A couraça a distancia das crianças e de si mesma, leva a uma posição cômoda, de se colocar fora do problema e desejar que ele se resolva logo, que nesse caso é a saída das crianças para outra escola. Como se isso resolvesse o problema. Novas turmas vão vir e, com elas, todas essas questões vão reaparecer, enquanto ela não encarar que a questão está na forma como se coloca diante do problema.

O desconhecimento do outro e a couraça permitem uma vida de exterioridade, na qual o homem se desconecta do encontro com o outro. Sem esse encontro, ele se volta cada vez mais para si, para suas necessidades, para seus gostos, opiniões, conhecimentos, experiências, dobra-sesobre-si-mesmo. Sem encontro, seu olhar sobre o outro se constitui cada vez mais a partir de si, ele isola-se em si e em seu modo de conhecer o mundo. Seu isolamento sobre si mesmo resulta em formas de relação com o outro distantes de sua inteireza. Ele o vê por vieses a partir de si, o que produz a discriminação, o estereótipo e o preconceito.

\section{5 "Perdeu o direito, Cá?" - DISCRIMINAÇÃO, ESTEREÓTIPOS, PRECONCEITO E INDIFERENÇA}

[No pátio do recreio] Vi uma menina ser xingada pelo colega de 'neguinha da rampa' por esta ter esbarrado em seu grupo, que brincava em um dos cantos do pátio. 
A menina xingada (Kiara) baixou a cabeça e voltou para a sala de aula apesar de ainda estar no horário do recreio. Porém, nesse meio tempo, a colega Abayomi foi tomar satisfação com o grupo que agrediu a colega. Indignada, falou: 'Vocês são uns idiotas! Acham que são melhores do que os outros, por quê? Não são! São é pior! Quem não respeita os outros é gente má! E o que é que tem ser negra e trabalhar na rampa? É algum crime?' (LIMA, 2006, p. 125).

$\mathrm{Na}$ situação acima, dois momentos ocorrem. O primeiro é vivido por Kiara, que sofre o preconceito, a discriminação. Já o segundo tem como sujeito da ação Abayomi, que acolhe Kiara, colocando-se em seu lugar. E o silenciar de Kiara diz muito. Expressa uma ausência, quando a voz deveria se fazer presente. Uma voz contra o preconceito e contra a discriminação. De alguma forma, pode-se dizer que Kiara estabeleceu uma relação com os colegas que a xingaram, pois foi atingida pela palavra dirigida e a esta respondeu com o silêncio. Contudo, seu silêncio não a impede de sofrer. O silêncio aparentemente protege, mas não resolve a questão. É preciso enfrentar aquilo que agride para impedir que essas situações permaneçam. Mais que isso, faz-se necessário viver internamente a dor para que a tristeza não leve a indiferença.

Enquanto Kiara tem uma atitude passiva, de se ausentar da relação, Abayomi reage à palavra dirigida a Kiara, fazendo-se presente. Somente quando se é presença a si mesmo é que pode tornar-se presente aos outros, acolhendo-os incondicionalmente em sua alteridade (ZUBEN, p. XVI, in BUBER, 2003). Há entre Abayomi e Kiara uma relação de amizade, que é uma atitude de inclusão, "uma relação dialógica, fundada na experiência concreta e recíproca daquele que inclui o outro" (Buber, 2004, p. 29)1. Essa relação motiva Abayomi a se posicionar perante o silêncio de Kiara, que, por não expressar verbalmente o que sente, em lugar de ser, parece ser.

Buber (2009, p. 141) fala sobre a dualidade do ser e do parecer que permeia a vida entre os homens no plano do inter-humano. O parecer é "a vida a partir da imagem, uma vida pelo que se quer parecer" (BUBER, 2009, p. 141). Essa aparência não é só o que se quer parecer, mas o que se vê na superficialidade redutora. Para o autor, o olhar analítico que predomina hoje nas relações é também redutor porque "quer reduzir a multiplicidade da pessoa [...] a estruturas esquematicamente abrangíveis pela vista e recorrentes" (BUBER, 2009, p. 147).

A relação inconsistente e redutora é a geradora da discriminação que se baseia em estruturas "abrangíveis pela vista". O que se vê e sequer se sabe o que é ou como é

\footnotetext{
1 Original em espanhol. Tradução das autoras.
}

na inteireza do ser. Redução ao que é recorrente possibilita os estereótipos que delineiam as marcas externas e imprecisas para a relação. De acordo com o que se vê, separa-se e se marca pela superficialidade. A marcação que se dá na superficialidade e não conhece o sujeito por trás da aparência cria e nutre preconceitos. E o problema maior é quando a superficialidade da relação impede de ver o outro, instaurando-se a indiferença. Toledo (2010) apresenta uma situação entre crianças e professores que ocorre no pátio da escola, nos preparativos para a festa junina.

[Na parte coberta do pátio, ao lado da quadra de esportes] Duas turmas de 4 anos estão sentadas no chão enquanto as professoras decoram a quadra para a festa julhina, pendurando os 'trabalhinhos': desenhos mimeografados coloridos pelas crianças que as professoras recortaram, colaram em CDs e amarraram em um fio de barbante. Após um tempo, as crianças começam a ficar impacientes e inquietas. Levantamse, conversam e brincam entre si. Quando se sentem incomodadas, as professoras falam:

- Dá para parar?

- Senta! Que coisa chata, você não está vendo que a gente está arrumando a festa?

Algumas crianças foram repreendidas várias vezes. Depois de repreendê-la várias vezes, uma das professoras pegou Ca pelo braço, levou-a até o outro lado da quadra e colocou-a sentada, sozinha, num dos bancos de cimento. Ju, ao ver sua irmã gêmea sentada, grita:

- Perdeu o direito, $\mathrm{Ca}$ ?

As crianças ficaram sentadas vendo as professoras decorarem a quadra por cerca de quarenta e cinco minutos (Toledo, 2010, p. 50).

As professoras estão indiferentes às crianças. Executam suas tarefas e as deixam esperando por um bom tempo. Não há um planejamento que envolva as crianças. Elas são deixadas no pátio, esquecidas, enquanto a tarefa é cumprida.

Embora Buber não apresente um conceito de indiferença, trata da questão ao se referir às situações em que não se sente nem amor e nem ódio. Estas estão no limite do entrar-em-relação, o que é bastante preocupante. Não se pode admitir que haja nas escolas a indiferença, por ser esta sinal de ausência da relação. Mais que desconhecimento do outro, a indiferença marca uma atitude de total não responsabilidade pelo outro. Como educadores, os professores são responsáveis por dizer algo a seus alunos, por darem uma resposta a eles. "A relação educativa é uma relação puramente dialógica" (BUBER, 2004, p. 26) 2 .

\footnotetext{
2 Original em espanhol. Tradução das autoras.
} 
Esta, como toda relação, comporta momento de amor e ódio, mas jamais de indiferença.

Nesse sentido, tratar desses temas é penoso. Seria muito mais interessante se fosse possível trazer apenas experiências positivas, que dão visibilidade às crianças. Mas isso seria ignorar a realidade com a qual se depara ao estudar o material selecionado. Como a intenção foi fazerse presente diante das situações encontradas, conclui-se que tratar dessas questões era um dever.

\section{CONSIDERAÇõES FINAIS}

Revisitar esses trabalhos permitiu abrir conversas sob outros ângulos. Considera-seque um autor quer ser lido e criticado, no sentido de dirigir a palavra a ele. E tevese a possibilidade de dialogar com diferentes trabalhos e diferentes campos, encontrar recorrências e perceber que há pontos de contatos a serem analisados. Nos recortes citados, observou-se que as situações que mais se aproximaram do dialógico, da alteridade, do respeito e do reconhecimento envolveram interações de/entre criançascrianças e crianças-pesquisador e monitor (durante visita ao museu); e as situações que mais se aproximaram do desconhecimento do outro, da couraça, discriminação, estereótipo, preconceito e indiferença referiam-se às práticas de professores e às interações dos professores com as crianças. Esses achados suscitam questionamentos sobre práticas pedagógicas, formação profissional, concepção de educação e infância que permeiam as relações na escola.

Buber, mais que uma fonte de análise, serviu de referência para observar o humano. Reconhecer que, mesmo diante de tantas situações de desconhecimento do outro, é possível encontrar momentos de alteridade. Não há ser humano que seja complemente bom ou ruim. Todos são feitos de dualidades. $\mathrm{O}$ exposto torna evidente o quanto se está fechado, cada um em si mesmo, nos próprios conceitos, que, não revistos, viram preconceitos. Não há como educar, sem abertura, sem acolhimento, sem que se estabeleça o entre. É preciso, primeiro, abrir-se para ir ao encontro do outro.

Foi feito esse movimento, abrindo-se esses trabalhos e pincelando pequenos fragmentos, que foram convertidos em um Isso. Foram analisados, comparados e registrados neste artigo, a fim de ganhar força e tornarem-se presentes, permitindo se falar das relações escolares de outra forma.
A intenção não foi dar uma melhor interpretação ao universo pesquisado, mas oferecer mais uma dentre tantas possíveis.

\section{REFERÊNCIAS}

BUBER, Martin. Eu e tu. Tradução, introdução e notas de Newton Aquiles Von Zuben. 6. ed., revista. São Paulo: Centauro, 2003.

BUBER, Martin. El caminho del ser humano y otros escritos. Salamanca: Kadmos, 2004.

BUBER, Martin. Do diálogo e do dialógico. Tradução de Marta Ekstein de Souza Queiroz e Regina Weinberg. São Paulo: Perspectiva, 2009.

FREIRE, Eliane Fazolo. Pelas telas de um aramado: educação infantil, cultura e cidade. Tese (Doutorado em Educação) Departamento de Educação, Pontifícia Universidade Católica do Rio de Janeiro, PUC-Rio, 2008.

LIMA, Maria Batista. Práticas cotidianas e identidades étnicas: um estudo no contexto escolar. Tese (Doutorado em Educação) - Departamento de Educação, Pontifícia Universidade Católica do Rio de Janeiro, PUC-Rio, 2006.

MAIA, Marta Nídia. Educação infantil: com quantas datas se faz um currículo? Dissertação (Mestrado em Educação) Departamento de Educação, Pontifícia Universidade Católica do Rio de Janeiro, PUC-Rio, 2011.

MOURA, Maria Tereza Jaguaribe Alencar de. A. Arte e infância: um estudo das interações entre crianças, adultos e obras de arte em museu. Dissertação (Mestrado em Educação) - Departamento de Educação, Pontifícia Universidade Católica do Rio de Janeiro, PUC-Rio, 2005.

OLIVEIRA, Cássia Maria Baptista de. É pecado desenhar Deus? Um estudo sobre práticas disciplinares com crianças de uma creche comunitária e de uma escola dominical. Dissertação (Mestrado em Educação) - Departamento de Educação, Pontifícia Universidade Católica do Rio de Janeiro, PUC-Rio, 1998.

TOLEDO, Maria Leonor Toledo. Relações e concepções de crianças com/sobre a natureza: um estudo em uma escola municipal. Dissertação (Mestrado em Educação) Departamento de Educação, Pontifícia Universidade Católica do Rio de Janeiro, PUC-Rio, 2010.

ZUBEN, Newton Aquiles Von. A. V. Introdução. In: BUBER, Martin. Eu e tu. 10. ed. Tradução, introdução e notas de Newton Aquiles von Zuben. São Paulo: Centauro, 2003. p. 7-49.

Submetido em: 15/01/2015

Aprovado em: 20/01/2016 